\title{
The Business Model and Protection of Broadcasting Rights of Sports Events Under the Internet Environment
}

\author{
Shanshan $\mathrm{Yu}^{1 *}$, Zhide $\mathrm{Zhou}^{1,2}$ \\ ${ }^{1}$ School of Intellectual Property, Guilin University of Electronic Science and Technology, Guilin 541004, China \\ ${ }^{2}$ Intellectual Property Research Institude, Xiamen University, Fujian 361005, China
}

\begin{abstract}
The rapid development of network technology has brought profound changes to all sectors of society. The relaxation of national policies and the surge of sports demand have made the sports industry undergoing profound changes. The broadcast of sports events in the network environment has strong immediacy and interactive advantages, which not only brings new experience to the audience, but also causes frequent infringement. As the domestic and foreign regulations on the nature of sports broadcast rights are not clear, the judicial judgment of sports infringement is not uniform. This paper introduces the background of sports event broadcast under the network environment, and further explores the problems in the process of sports event broadcast by analyzing the development of its business model, and then puts forward some suggestions for sports event broadcast in China.
\end{abstract}

\section{Background}

With the increase of people's awareness of sports and fitness, the consumption of participating in sports events has been increasing, and the consumption structure has changed. With the support of policies and the market, sports events have developed rapidly. A perfect business model can improve the commercial and economic benefits of sports events. The innovation of business model of sports broadcast can stimulate the development of sports industry and cause many copyright disputes. From a single media copyright subject in the past to a combination of media copyright, event ownership, event operation and other rights, the competition subject and object are constantly changing. The high cost of broadcasting has become an important source of income for the sports industry. Sports events can increase their income through broadcasting or delayed broadcasting and maximize their economic benefits. The broadcast market of sports events in China is monopolized, and there are many disputes about the nature of live broadcast and broadcast of sports events. This phenomenon seriously harms the interests of the right subjects, and the disputes about the broadcast rights of sports events are increasing, which causes the discussion in the academic and material circles.

\section{Broadcasting of sports events and infringing acts}

\subsection{Broadcast of sports events}

Broadcast rights are the core of competitive sports, the concept first coined by the American Baseball League in 1921, before sports were considered news and most American broadcasters refused to pay for them. Today's sports should not only be carried out in accordance with the unified rules of the contest, also contains other activities related to sports ${ }^{[1]}$. The broadcast right of sports events refers to the right granted by the organizer of a sports event to the broadcaster to live broadcast the video of sports events after receiving the corresponding consideration from the broadcaster, which is transmitted to the majority of non-specific subjects through the program of sports events. The rights of broadcast of sports events can be analyzed from three aspects: Firstly, sports events are the basis for the generation and existence of other rights. The organizers of sports events spend money, technology and manpower, which makes a series of rights belong to the organizers. Secondly, in order to maximize their own interests, the organizers of sports events will produce sports events, or allow others to broadcast or produce sports events to spread to more people. Thirdly, the above two subjects will also authorize other subjects to make and broadcast sports events. There are two forms of sports event broadcast: direct acquisition and indirect

\footnotetext{
* Corresponding author. Email: 645387486@qq.com
} 
acquisition. Under the network environment, is the use of P2P streaming media technology will broadcast live sporting events show synchronous uploaded to the user terminal equipment, to form a temporary copy file and stored in the temporary storage, and then the real-time broadcast to the public.

\subsection{Infringing acts in the broadcast of sports events}

\subsubsection{The stealing of broadcasts of traditional games}

The progress of science and technology reduces the difficulty and cost of online video broadcasting websites. Without obtaining the copyright of sports events, many new media companies intercept the video signals of their sports events and upload the sports events to the video broadcasting websites they have established, so as to meet the audience's demand and create profits by pirated broadcasting. From the perspective of infringement, network organizations use information and communication network technology to synchronously retransmit TV media programs, intercept TV media signals or generate new digital signals, which is the replication of TV media event signals. It involves the pirated broadcast of TV program contents and program signals, and infringes the copyright and broadcasting organization rights of TV media.

\subsubsection{The stolen broadcast to the same kind of broadcasting platform}

New media sports broadcasting business hotlinking generally takes advantage of the technical loopholes in the video streaming service mechanism to tamper with the play or download link and link the network video player to its own website. Users only need to visit the stolen broadcast website and can watch the network video of the games without visiting the regular network video playing website, which damages the potential browsing of the regular network video playing website. This kind of improper or illegal use of network video avoids the business usage charging and then USES the content products that should be charged for free ${ }^{[2]}$. There is no doubt that this through grasping new media sports video website address, set in the sports event broadcast on the video of the client, not only occupy the linked website broadband, and the hardware and software such as infringing the copyright content, consumes system resources of sports copyright owners, and could lead to a hole billing. In the hotlinking-led and operated hotlinking behavior of new media sports event broadcasting, the hotlinking is not aware of the video stream transmitted from the server and is used passively as a "tool". The hotlinking implements the network content providing behavior and steals the rights of work disseminators.

\section{Discussion on the business model of network broadcast of sports events}

Sports program is the production of live sports events and broadcast by the media to the audience. The broadcast content involves the selective shooting of the scene shots and seats, the editing and arrangement of the video content, the participation of the host and commentary, and finally the combination of a series of words, images, videos and audio to produce a series of ornamental and artistic TV programs. Under the network environment, the production and broadcasting of sports program involves multiple subjects, mainly including the organizers, producers and players of sports events.

\subsection{Three modes}

The whole process from authorized shooting, production and broadcasting of sports event programs is complex and diverse ${ }^{[3]}$. Due to the different status and nature of program producers, the ownership of the copyright of sports event programs varies, which can be divided into the following three situations.

Mode 1: The copyright of sports event programs shall be enjoyed by the event organizers. The producer of sports event programs is a part of the program organizers of sports events (Figure1).

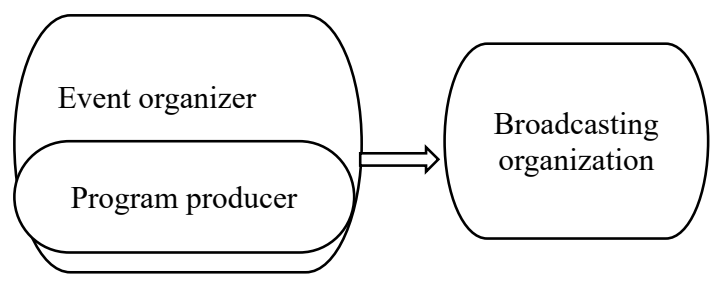

Figure1. Mode 1

Mode 2: The program producer is part of the broadcasting organization. The event organizer allows its relevant staff to enter and film the sports event program, and then transfers its materials to the broadcasting organization for editing, adding program commentary, picture skills and other factors. Therefore, the broadcast organizer enjoys the copyright of the sports event program

(Figure2).



Figure2. Mode 2

Mode 3: Sports program organizers, producers, three independent broadcast, sports organizers authorized 
producers to enter the field of film, production, producers will be taken by the program empowers players to play, this kind of mode, the sports event producers, enjoy the copyright of sports programs (Figure 3 )



Figure3. Mode 3

\subsection{The innovation of business model}

Scientific and technological progress, market and value chain are the important influencing factors of Internet sports media business model reform. With the development of the society, the business model is constantly innovated, which influences the development of sports events and programs. First, technological progress has changed the original form of sports program. Nowadays, sports program is no longer a wobbling between two or three shots in the early days, but a wonderful "work" of form and content displayed by many techniques. More and more high and new technologies are gradually applied to increase the sense of spot in sports broadcast. With the continuous development of intelligent terminal technology, the traditional TV terminal and PC terminal have developed into today's mobile terminal, and the speed and quality of broadcast has been gradually improved to better meet the needs of users. Second, the sports industry chain has been reformed, and the single and one-way value chain has been gradually replaced ${ }^{[4]}$. Nowadays, under the network environment, more attention is paid to the needs of audiences. Based on the needs of users, sports event programs pay more attention to the experience of audiences and pay more attention to their spiritual enjoyment. The scarcity of sports event copyright makes the cost of sports event program soar, and the high copyright fee increases the operating cost and reduces the profit. Third, the sports market continues to innovate. With the relaxation of sports broadcasting policies, more competitors are piling into the industry. The progress of network technology makes the traditional industry barriers no longer exist, and the constantly developing market environment puts forward higher requirements for the sports market. More commercial elements have been added to the existing sports programs, such as real-time commentary on the games, audience sweepstakes, player interaction.

\section{The dilemma of protecting the broadcast rights of sports events}

\subsection{The identification of nature of sports programs}

The root of broadcasting rights is to determine the nature of sports programs. If the sports event program belongs to the work, the broadcasting right belongs to the copyright content; If sports program belongs to the object of neighbor right, the broadcast right belongs to the content of neighbor right. Sports program is composed of many factors, including the sports event itself, commentary and commentary. In China's judicial practice, different courts have made different judgments on the nature of sports programs. Among them, most believe that the originality of sports events programs is limited and does not constitute a work, but belongs to video products. But even if a court considers a sporting event to be a video, live broadcast over the Internet is not protected by the rights of the video producer. Because the content of the video producer right only includes the right of reproduction, distribution, rental, information network transmission right ${ }^{[5]}$. Based on the right of information network transmission, audiences can watch the program at the time and place they choose, which is inconsistent with the connotation of network real-time broadcast right. The latter can only make the audience watch the program in a specific time, so it does not belong to the protection of the right of information network transmission.

\subsection{Interpretation of the extension of the right of broadcast organizers}

Internet service providers are authorized by TV stations to broadcast in real time. At present, the protection scope of broadcast organizer right is small, and the network realtime broadcast behavior cannot be controlled. Then, can the right be extended to the interpretation of the provisions of the retransmission to apply to the network environment? In the judicial practice of China, there are two opposite opinions on whether retransmission can be applied to the network environment. One view holds that broadcasting can cover the Internet environment, while the other holds that broadcasting organizations cannot control the Internet. In addition to the right of broadcast organizers include retransmission, the right of broadcast copyright also includes retransmission. The right to broadcast is borrowed from the Berne Convention. Since the protection of copyright and neighboring rights should be equal, when the broadcasting right does not apply to the network environment, the retransmission of neighboring rights naturally does not apply to the network environment either. 


\section{Suggestions on the protection of broadcast rights for sports events}

\subsection{Expand interpretation of broadcast organizers' broadcast rights}

The scope of protection of the right of broadcast organizer is limited to wired and wireless means, and the subject of network broadcast does not belong to the category of broadcast organizer. In this regard, in addition to amending the types of works through legislation, judicial interpretations can also be issued to expand the interpretation of the right of broadcast organizer, and the act of network broadcast can be included in the scope of protection of the right of broadcast organizer ${ }^{[6]}$. To endow broadcasting organizations with active civil rights is conducive to promoting the establishment of market order of sports event broadcast.

\subsection{Clarify the legal nature of sports broadcast rights}

The broadcasting right of sports events is an economic right generated by the event organizers based on the control of the game resources. From the perspective of economics, the interest of broadcasting right can bring great economic value to the game organizers, so as to compensate for the cost invested in organizing the games [7]. Therefore, it is necessary to protect this form of interest. In practice, the broadcast rights of sports events are generally agreed through the relevant articles of association. Such rights arising from the articles of association of sports events are not legal rights, but based on the contractual rights, which are difficult to fight against the third party. Therefore, it is conducive to the protection of online sports programs to clarify the legal status of sports broadcast rights, fully protect sports broadcast rights, and let broadcasting organizations regulate illegal online broadcast behaviors by using sports broadcast rights.

\subsection{Coordination among different agencies and departments}

Nowadays, there are frequent infringement incidents of sports event programs. In the absence of amendment of the current copyright law, the infringement phenomenon of sports event programs cannot be well maintained only by relying on the judicial department. Therefore, it needs the coordination and cooperation of the judicial department, administrative department, industry association and other organizations and departments to form a powerful system of rights protection. All departments should strengthen the protection of sports events and programs under the network environment, actively respond to existing problems and challenges, and jointly create a good environment for sports events.

\section{Conclusion}

With the rapid development of sports industrialization in China, the copyright disputes of sports event programs occur constantly in practice. The study on this issue is not only necessary in the field of copyright protection, but also necessary to regulate the development of sports events and the whole sports cause. Network technology and the development of science and technology makes the sports program of innovative, more can satisfy the audience's spiritual demand, accelerate the development of the sports program broadcast. Therefore, we should strengthen the protection of sports events and programs to create a good environment for the development of the industry.

\section{Acknowledgment}

This research was financially supported by the Innovation Project of Guilin University of Electronic Technology Graduate Education No.2020YCXS106 and Guilin University of Electronic Science and Technology Internet + Intellectual Property Rights Protection Research Think Tank (Guidian Science [2019] No.3).

\section{References}

1. Zhang xf. Copyright protection of disseminators' rights and interests in sports events in interpretive theory [J]. Modern law,2019,41(06):149-163.

2. Hu Jingjing. Protection of "signal" or "picture": a study on the protection path of live broadcast of sports events [J]. Northern science of law,2019,13(03):29-40.

3. Wu Yuhui. New Path for Legal Protection of Sports Broadcast Rights $[\mathrm{J}]$. Intellectual Property Rights,2018(12):31-40.

4. Lu Liqiang. Development of Sports Industry and Intellectual Property Protection [J]. Electronic Intellectual Property,2018(03):64-69.

5. Feng Chun. Reflections on the dichotomy of sports broadcast rights [J]. Law forum,2016,31(04):126-132.

6. Juma. Legal protection of sports broadcast rights from the perspective of interest balance [J]. Hebei law school,2015,33(02):166-174.

7. Geng Xieqi. On the Legal Protection of Sports Broadcast Rights [J]. Legal System and Society,2017(05):73-74. 